\title{
Special issue on Structural Priming in Less-Studied Languages and Dialects: Introduction
}

\author{
Martin J. Pickering • Holly P. Branigan
}

Published online: 21 November 2019

(C) Springer Nature Singapore Pte Ltd. 2019

\begin{abstract}
We provide a brief introduction to the special issue of the Journal of Cultural Cognitive Science entitled Structural Priming in Less-Studied Languages and Dialects. Structural priming is the tendency for people to use linguistic structures that they have recently encountered. It has been extensively investigated in English and a few related languages, but there has been very little work on the vast majority of languages around the world. We are pleased to publish six papers concerned with Turkish, Norwegian, Irish, Italian, and two varieties of Portuguese. They are informative about many issues in linguistic representation and processing and help diversify psycholinguistics and the cognitive sciences more generally.
\end{abstract}

Structural priming is the tendency for people to use linguistic structures that they have recently encountered. Since its discovery by Bock (1986), it has become one of the main experimental methods to understand the nature of linguistic representation and how people produce and comprehend language. Priming has been demonstrated in a number of languages, and indeed between languages in bilinguals, but the great majority of work has focused on

M. J. Pickering $(\bowtie) \cdot$ H. P. Branigan

Department of Psychology, University of Edinburgh, 7

George Square, Edinburgh EH8 9JZ, UK

e-mail: martin.pickering@ed.ac.uk
English or closely related languages (Pickering and Ferreira 2008). However its value as a method is much wider than this. The study of priming across the full range of languages and dialects in the world would prove invaluable in understanding what aspects of processing and representation hold across languages and what aspects are specific to particular languages, and should therefore help the development of both psycholinguistic and linguistic theory.

We are therefore very pleased that the Journal of Cultural Cognitive Science is publishing a special issue on Structural Priming in Less-Studied Languages and Dialects. The value of taking structural priming beyond English and closely related languages should be apparent. Our focus in the language sciences is to understand languages in all their diversitywhether from the point of view of how they are represented, used, acquired, or break down. Structural priming can provide evidence about all of these different dimensions of the language sciences, and therefore it is important to use it to study the full range of languages and dialects. Needless to say, we can and we should address languages that go beyond those spoken by very large numbers of people, by socially dominant groups, in industrialised countries, or corresponding to the formal or written register.

One claim is that structural priming can inform us about the nature of linguistic representation-and indeed that it has many advantages over acceptability judgements (Branigan and Pickering 2017). If processing one stimulus affects the processing of another 
stimulus, then those stimuli share some aspects of their representation. If those stimuli are linguistic in nature, then they share some aspects of linguistic representation. For example, Bock and Loebell (1990) found that people were more likely to produce the girl is handing a paintbrush to the boy after the wealthy widow drove an old Mercedes to the church than after the wealthy widow sold the church an old Mercedes. This study showed that participants repeat syntactic structure (i.e., a "prepositional object" structure involving verb, noun phrase, and prepositional phrase) even though the prepositional phrase in the prime refers to a location whereas the prepositional phrase in the target refers to a recipient. What this suggests is that priming may discriminate structural representations-in this case, that priming discriminates a level of representation concerned with syntactic information that is independent of semantic information. In other cases, it may conversely discriminate a level of representation concerned with semantic information that is independent of syntactic information, as when Vernice et al. (2012) showed that Dutch speakers tended to repeat which thematic role was emphasized across sentences that differed in syntactic structure (e.g., Degene die hij slaat is de cowboy, "The one who he is hitting is the cowboy" primed Het meisje wordt overspoeld door de golf, "The girl is being soaked by the wave").

So structural priming appears informative about different levels of linguistic representation. The study of priming in languages less closely related to English should therefore provide information about a wide range of aspects of linguistic structure-both from the point of view of understanding the representation of particular constructions, and in order to determine if accounts of linguistic representations hold across languages. To address the second issue, it is particularly interesting to look at cross-linguistic priming in bilinguals. Recently, Huang et al. (2019) found that participants tended to produce Mandarin sentences such as Niuzai di-gei xiaotou yige pingguo, 'The cowboy passes the thief an apple' after hearing the chef gives the priest a ball, but tended to produce Niuzai di-le yige pingguo gei xiaotou, 'The cowboy passes an apple to the thief' after hearing the chef gives a ball to the priest. Such priming suggests that Mandarin datives share linguistic representations with English datives. From these examples, we cannot of course conclude exactly how particular languages are represented, but priming provides us with a method for doing so, and so the study of priming across many different languages allows us to understand the nature of linguistic representation in general-for example, whether there are language universals or not (see Evans and Levinson 2009). It is therefore very important to investigate priming in less-studied languages.

Of course, it is possible to make similar arguments about aspects of processing, acquisition, and breakdown. In fact, the majority of studies of priming have investigated how aspects of language production take place. Studies such as Bock and Loebell (1990) suggest that syntax has some autonomy from semantics, and at the same time suggest that semantics may be constructed independently of syntax (Bock and Levelt 1994). They provide some evidence for the construction of constituent structure without closedclass elements (Bock 1989) and against the construction of a syntactic representation that has not been specified for linear order (Pickering et al. 2002). But languages vary widely in their syntactic properties, and it might be that speakers of languages with radically different properties from English produce utterances via different processing stages. So we can use priming to investigate whether there are universal principles underlying language production-and in the same way we can investigate comprehension, acquisition, or breakdown.

All-in-all, structural priming has become one of the most popular methods in the language sciences and clearly has enormous potential. But it has been limited to a small range of languages, for obvious reasons. Most studies use English, and many of the rest use German or Dutch. There have been a number of recent studies using East Asian languages, most often Mandarin Chinese, and a few isolated studies in other languages, including ASL (Hall et al. 2015). Interestingly, priming appears to occur to a fairly similar extent wherever it has been investigated. But this situation is wildly imbalanced-indeed, much more so than linguistics as a whole, which has documented and investigated languages around the world. Our special issue provides an initial attempt to rectify this situation and therefore is highly appropriate for the Journal of Cultural Cognitive Science. In fact, the languages studied in this special issue are relatively small in number-Turkish, Norwegian, Irish, Italian, and two varieties of Portuguese-but they represent a typological range (e.g., verb-initial vs verb-final, agglutinative 
vs non-agglutinative), and demonstrate some of the novel questions that a cross-linguistic programme of research can address.

\section{The papers in this issue}

Using Turkish, Mercan and Hohenberger (2019) found priming of the choice of two constructions that both involve noun phrases containing a possessive. In the "noun phrase" construction, the possessive is followed by a noun (translating as Ayse's voice); in the "noun clause" construction, the possessive is followed by a complement clause (translating as Ayse's leaving or Ayse's having left). The findings indicate that these constructions are distinguished at a level of representation that priming is sensitive to. The authors argue that possessive noun clauses and noun phrases have different syntactic structures, even though on the surface they play similar roles in sentences and involve similar complex morphology, and emphasise how structural priming can inform linguistic theory. In addition, the study demonstrates priming in an agglutinatively complex, verb-final language.

Ziegler et al. (2019) also investigated priming across constructions with a similar surface form. They considered the locative alternation in Brazilian Portuguese (translating as the girl rubbed the table with polish vs. the girl rubbed polish on the table). Priming occurred even though both sentences involve the same order of constituents (noun phrase, verb, noun phrase, prepositional phrase). Therefore, the results support semantic structural priming, and suggest that such priming occurs similarly to the way it occurs in English (Chang et al. 2003), despite the fact that Brazilian Portuguese is verb-framed (i.e., information about path and manner tends to be expressed in a verb rather than a separate phrase).

Mercan and Hohenberger emphasized using structural priming to investigate syntactic structure and Ziegler et al. emphasized its use to investigate semantic structure. Vernice and Hartsuiker (2019) concentrated on the mapping between the two levels, and considered how priming could help discriminate theories of how this mapping might occur. In their study, they used structural priming to modulate a default bias to assign agents as subjects, and found that priming increased the proportion of passives overall. They found priming of transitive sentences (actives/passives) in Italian and demonstrated that it was relatively long-lasting (as in Bock and Griffin 2000). But more importantly, they found that speakers produced more actives when agent and patient were both animate than when they were both inanimate.

Fernandes et al. (2019) investigated the effects of exposure to multiple prime sentences in Portuguese sentence comprehension. Listeners tended to fixate the referent consistent with the primed interpretation when listening to a sentence that was temporarily ambiguous between a high- and low-attached interpretation after hearing a single disambiguated prime, but at the referent consistent with the non-primed interpretation after multiple primes. The authors suggest that the relationship between processing linguistic and visual behaviour is complex, and is influenced by a range of factors that can include linguistic experience, attentional resources, and visual features.

The final two papers are concerned with crosslinguistic priming. Mercan and Simonsen (2019) investigated whether two groups of bilinguals repeated transitive structure from Norwegian to English and from Norwegian to Turkish. The word order of passives is similar between Norwegian and English but very different between Norwegian and Turkish. The study did not reveal priming for either group. However, they did find that Turkish speakers were more likely to topicalize or relativize the patient if the agent was inanimate than if it was animate, a finding that is in accord with evidence from English (e.g., Clark 1965).

Favier et al. (2019) investigated priming of dative and transitive sentences from Irish to English. There was a small tendency to produce more English prepositional datives after Irish prepositional datives (translating as gave the pirate cake to the boxer), as compared to conjunctions (translating as a boxer, a pirate, and a cake)-an effect that was larger for participants with higher self-rated proficiency in Irish. What is notable is that priming occurred even though word order is different in Irish and English. A second experiment found dative priming in English. 


\section{References}

Bock, J. K. (1986). Syntactic persistence in language production. Cognitive Psychology, 18(3), 355-387.

Bock, K. (1989). Closed-class immanence in sentence production. Cognition, 31(2), 163-186. https://doi.org/10.1016/ 0010-0277(89)90022-X.

Bock, K., \& Griffin, Z. M. (2000). The persistence of structural priming: transient activation or implicit learning? Journal of Experimental Psychology: General, 129, 177-192. https://doi.org/10.1037/0096-3445.129.2.177.

Bock, K., \& Levelt, W. J. M. (1994). Language production: Grammatical encoding. In M. A. Gernsbacher (Ed.), Handbook of Psycholinguistics (pp. 945-984). San Diego, CA: Academic Press.

Bock, K., \& Loebell, H. (1990). Framing sentences. Cognition, 35, 1-39. https://doi.org/10.1016/0010-0277(90)90035-I.

Branigan, H. P., \& Pickering, M. J. (2017). An experimental approach to linguistic representation. Behavioral and Brain Sciences, 40, e282. https://doi.org/10.1017/ S0140525X16002028.

Chang, F., Bock, K., \& Goldberg, A. E. (2003). Can thematic roles leave traces of their places? Cognition, 90, 29-49.

Clark, H. H. (1965). Some structural properties of simple active and passive sentences. Journal of Verbal Learning and Verbal Behavior, 3, 370-375.

Evans, N., \& Levinson, S. C. (2009). The myth of language universals: language diversity and its importance for cognitive science. Behavioral and Brain Sciences, 32(5), 429-448. https://doi.org/10.1017/S0140525X0999094X.

Favier, S., Wright, A., Meyer, A., et al. (2019). Proficiency modulates between- but not within-language structural priming. Journal of Cultural Cognitive Science. https://doi. org/10.1007/s41809-019-00029-1.

Fernandes, E. G., Coco, M. I., \& Branigan, H. P. (2019). When eye fixation might not reflect online ambiguity resolution in the visual-world paradigm: structural priming following multiple primes in Portuguese. Journal of Cultural Cognitive Science. https://doi.org/10.1007/s41809-019-000219.

Hall, M. L., Ferreira, V. S., \& Mayberry, R. I. (2015). Syntactic priming in American Sign Language. PLoS ONE, 10(3), $\mathrm{e} 0119611$.
Huang, J., Pickering, M. J., Chen, X., Cai, Z., Wang, S., \& Branigan, H. P. (2019). Does language similarity affect representational integration? Cognition, 185, 83-90. https://doi.org/10.1016/j.cognition.2019.01.005.

Mercan, G., \& Hohenberger, A. (2019). Structural priming in the production of Turkish possessive noun phrases and noun clauses. Journal of Cultural Cognitive Science. https://doi.org/10.1007/s41809-019-00043-3.

Mercan, G., \& Simonsen, H. G. (2019). The production of passives by English-Norwegian and Turkish-Norwegian bilinguals: a preliminary investigation using a cross-linguistic structural priming manipulation. Journal of Cultural Cognitive Science. https://doi.org/10.1007/s41809019-00040-6.

Pickering, M. J., Branigan, H. P., \& McLean, J. F. (2002). Constituent structure is formulated in one stage. Journal of Memory and Language. https://doi.org/10.1006/jmla.2001. 2824.

Pickering, M. J., \& Ferreira, V. S. (2008). Structural priming: A critical review. Psychological Bulletin, 134(3), 427-459. https://doi.org/10.1037/0033-2909.134.3.427.

Vernice, M., \& Hartsuiker, R. J. (2019). Mapping thematic roles onto grammatical functions in sentence production: evidence from structural priming in Italian. Journal of $\mathrm{Cul}$ tural Cognitive Science. https://doi.org/10.1007/s41809019-00044-2.

Vernice, M., Pickering, M. J., \& Hartsuiker, R. J. (2012). Thematic emphasis in language production. Language and Cognitive Processes, 27, 631-664. https://doi.org/10.1080/ 01690965.2011.572468.

Ziegler, J., Morato, R., \& Snedeker, J. (2019). Priming semantic structure in Brazilian Portuguese. Journal of Cultural Cognitive Science. https://doi.org/10.1007/s41809-01900022-8.

Publisher's Note Springer Nature remains neutral with regard to jurisdictional claims in published maps and institutional affiliations. 